\title{
Oxytocin receptor expression in human term and preterm gestational tissues prior to and following the onset of labour
}

\author{
D C Wathes, S C Borwick, P M Timmons, S T Leung and \\ S Thornton ${ }^{1}$
}

The Royal Veterinary College, Reproduction and Development Group, Boltons Park, Hawkshead Road, Potters Bar, Hertfordshire, EN6 1NB, UK

${ }^{1}$ University of Cambridge, Department of Obstetrics and Gynaecology, Rosie Maternity Hospital, Cambridge, CB2 2SW, UK

(Requests for offprints should be addressed to D C Wathes, Department of Veterinary Basic Sciences, Royal Veterinary College, Boltons Park, Hawkshead Road, Potters Bar, Hertfordshire, EN6 1NB, UK)

\begin{abstract}
Oxytocin receptor (OTR) mRNA expression has previously been demonstrated in human myometrium, decidua, chorion and amnion but the effect of gestational age and the onset of labour has not been determined in these individual tissues. Spatial OTR mRNA expression was examined by in situ hybridization and ligand binding was confirmed using autoradiography with the iodinated oxytocin antagonist $\mathrm{d}\left(\mathrm{CH}_{2}\right)_{5}\left[\mathrm{Tyr}(\mathrm{Me})^{2}, \mathrm{Thr}^{4}, \mathrm{Tyr}-\mathrm{NH}_{2}{ }^{9}\right]-$ vasotocin ( ${ }^{125} \mathrm{I}$-OTA). Tissue was collected at term (>37 weeks of gestation) or preterm (24-36 weeks of gestation) caesarean section and classified as labour (contractions every 5 min associated with cervical dilatation) or non-labour. OTR mRNA expression was measured as optical density units from autoradiographs. There was a highly significant $(P<0.001)$ effect of tissue type on expression of OTR mRNA with expression greatest in myometrium, low in decidua and chorion and not detected in placenta. Similar results were obtained with
\end{abstract}

the ${ }^{125}$ I-OTA-binding studies, indicating that the message was translated. Amnion had an apparently high level of both hybridization and ${ }^{125}$ I-OTA binding in some samples, but a lack of specificity prevented quantification of the signal in this tissue type. Term myometrium (labour and non-labour) had significantly higher $(P<0 \cdot 01)$ OTR mRNA expression than preterm myometrium, but there was no further increase in mRNA concentration associated with labour onset. In contrast, ${ }^{125}$ I-OTA binding in myometrium was already high at 33 weeks and did not increase further either later in pregnancy or with labour. In decidua there was no effect of gestational age or labour onset on OTR mRNA expression or ${ }^{125}$ I-OTA binding. In summary, OTR mRNA expression in the myometrium increased in late pregnancy whereas decidual expression was much lower and did not rise at term. Journal of Endocrinology (1999) 161, 143-151

\section{Introduction}

Preterm labour occurs in up to $10 \%$ of all human births and remains the major cause of perinatal morbidity and mortality. However, the processes initiating both term and preterm labour remain unclear. Oxytocin (OT), a potent uterotonic nonapeptide hormone, is known to act both directly and indirectly to stimulate uterine muscle contraction. Uterine sensitivity to OT increases dramatically around parturition but there is no significant increase in plasma OT concentration before or during labour (Leake et al. 1981, Thornton et al. 1992). There is, however, evidence from Northern blot analysis in the rat (Zingg et al. 1995) and human (Chibbar et al. 1993), that uterine synthesis of OT increases after the onset of labour. In situ hybridization analysis has indicated local production of OT mRNA in amnion, chorion and decidua (Chibbar et al. 1993). These findings suggest a paracrine action of OT in intrauterine tissues to regulate parturition.
Ligand-binding studies (Soloff et al. 1979, Fuchs et al. 1984) and Northern blot analyses (Kimura et al. 1996) have shown that the increase in sensitivity to $\mathrm{OT}$ is correlated with a concomitant up-regulation of uterine OT receptors (OTR). Both OTR concentration (Thorburn \& Challis 1979, Fuchs et al. 1982, Fukai et al. 1984) and OTR mRNA expression (Kimura et al. 1996) increase towards term in human myometrial tissue. OTR mRNA expression has also been identified in decidua and chorion tissues following delivery at term using in situ hybridization (Takemura et al. 1994). To date, OTR mRNA expression coupled with OT binding site concentrations has not been systematically compared in all gestational tissues from mid-pregnancy.

The aim of this study was to determine the effect of gestational age and the onset of labour on OTR mRNA expression and OTR binding. OTR mRNA expression in myometrium, decidua, amnion, chorion and placental tissue was determined by in situ hybridization. 
OT binding sites in these tissues were localized by autoradiography with an iodinated OT antagonist, $\mathrm{d}\left(\mathrm{CH}_{2}\right)_{5}\left[\mathrm{Tyr}(\mathrm{Me})^{2}, \mathrm{Thr}^{4}, \mathrm{Tyr}-\mathrm{NH}_{2}{ }^{9}\right]$-vasotocin $\left({ }^{125} \mathrm{I}\right.$-OTA $)$.

\section{Materials and Methods}

\section{Tissue collection and preparation}

Myometrium, decidua, chorion, amnion and placenta were obtained from 38 patients (following written informed consent) undergoing caesarean section either at term (37 weeks of gestation onwards) or preterm (24-36 weeks of gestation). Complete cross sections of uterine wall were taken whenever possible to include myometrium through to amnion in a single biopsy. The sampling site was the upper edge of the caesarean incision at the reflection of the parietal peritoneum. A separate biopsy was taken from the placenta immediately after delivery. The tissue was classified as labour or non-labour, with labour defined as contractions every $5 \mathrm{~min}$ associated with cervical dilatation. Tissue was immediately frozen in isopentane in liquid nitrogen and stored at $-80{ }^{\circ} \mathrm{C}$.

\section{Reagents}

Chemicals used were either from Sigma Chemical Co. (Poole, Dorset, UK) or Merck Ltd (Poole, Dorset, UK) unless otherwise stated.

\section{In situ hybridization}

Frozen samples were sectioned to $18 \mu \mathrm{m}$ and thawmounted onto poly-L-lysine-coated slides. Sections were fixed in $4 \%$ paraformaldehyde in $0.01 \mathrm{M}$ PBS, $\mathrm{pH} 7 \cdot 0$ for $5 \mathrm{~min}$, rinsed in $1 \times \mathrm{PBS}$ (three times for $2 \mathrm{~min}$ each) then sequentially dehydrated in 70 and $95 \%$ ethanol (5 min each). Sections were stored in 95\% ethanol at $4{ }^{\circ} \mathrm{C}$ until used.

OTR mRNA was localized using a ${ }^{35}$ S-labelled $45-$ mer oligonucleotide probe complementary to bases 876-921 of the human OTR cDNA (Inoue et al. 1994). The antisense sequence was 5'-TTC-CTT-GGG-CGC-GTT-GGCATC-CCA-GAC-GCT-CCA-CAT-CTG-CAC-GAA$3^{\prime}$. The corresponding sense sequence was used to indicate non-specific background hybridization.

The technique used was based on that of Stevenson et al. (1994). Sections were hybridized overnight at $42.5^{\circ} \mathrm{C}$ in a humid environment maintained with 50\% deionized formamide solution in $5 \times \mathrm{SSC}(1 \times \mathrm{SSC}$ is $15 \mathrm{mM}$ sodium chloride, $15 \mathrm{mM}$ sodium citrate). The hybridization buffer solution contained 110000 d.p.m. oligonucleotide probe end-labelled at the $3^{\prime}$ end with ${ }^{35}$ S-labelled dATP (ICN Chemicals Ltd, Thame, Oxfordshire, UK) using terminal deoxynucleotidyl transferase (from calf thymus, purified by fast protein liquid chromatography; Pharmacia Biotech, Milton Keynes, Bucks, UK) in 50\% deionized formamide, $4 \times$ SSC, $10 \%$ dextran sulphate, $5 \times$ Denhardt's solution, $0.2 \mathrm{mg}$ salmon sperm DNA $/ \mathrm{ml}, 0 \cdot 1 \mathrm{mg}$ polyadenylic acid $/ \mathrm{ml}, 0 \cdot 12 \mathrm{mg}$ heparin $/ \mathrm{ml}, 0.025 \mathrm{M}$ sodium phosphate $(\mathrm{pH} \mathrm{7.0)}$ and 0.001 M sodium pyrophosphate. Post-hybridization, samples were subjected to a low-stringency wash $(1 \times$ SSC, $0 \cdot 2 \%(\mathrm{w} / \mathrm{v})$ sodium thiosulphate pentahydrate solution at room temperature, agitating for $30 \mathrm{~min}$ ) followed by a higher stringency wash $\left(1 \mathrm{~h}\right.$ static at $\left.55^{\circ} \mathrm{C}\right)$, then rinsed and dehydrated $(1 \times \mathrm{SSC}, 0 \cdot 1 \times \mathrm{SSC}, 70$ and $95 \%$ ethanol, for $20 \mathrm{~s}$ each).

Slides were exposed for 14 days to Hyperfilm $\beta$-max (Amersham International plc, Amersham, Bucks, UK) in $\mathrm{X}$-ray cassettes to detect positive hybridization signals. Photographic emulsions were subsequently performed on individual slides as described by Stevenson et al. (1994) to confirm cellular localization of the signal. Following emulsion, slides were stained with haematoxylin and eosin.

\section{Autoradiography}

OTR binding sites were visualized using ${ }^{125}$ I-OTA (Bachem (UK Ltd), Saffron Walden, Essex, UK) as described previously (Ayad et al. 1991). Frozen sections $(18 \mu \mathrm{m})$ were thaw mounted onto chrome-alum-coated slides and incubated with $300 \mu \mathrm{l}{ }^{125}$ I-OTA alone $(0 \cdot 1-$ $0.4 \mathrm{nmol} / \mathrm{l})$ for the assessment of total binding or with $10 \mu \mathrm{mol} / 1$ unlabelled OT (Bachem) for the quantification of non-specific binding (NSB).

\section{Optical density (OD) measurements}

Two pairs of slides from each patient with two or three sections per slide were processed for in situ hybridization; one pair was hybridized with the antisense and the other with the sense probe. A further two pairs of slides from representative patients were treated with ${ }^{125} \mathrm{I}-\mathrm{OTA}$ alone (total binding) or with unlabelled OT (NSB) for the receptor-binding studies.

The intensity of label on each section was measured from the autoradiographs as OD measurements using a Seescan image analysis system (Seescan plc, Cambridge, Cambs, UK). The gestational tissue types (identified from haematoxylin and eosin slides) were outlined on each section and the program subtracted background OD of blank film to give an average OD for each outlined area, calibrated on a linear scale between $0 \cdot 01$ and $2 \cdot 1$. The OD values from the sense or NSB sections were subtracted from the antisense or total binding values to give an estimate of specific hybridization and binding respectively. An OD value of $<0.01$ was taken as the lower limit of detection for the purpose of statistical analysis. 


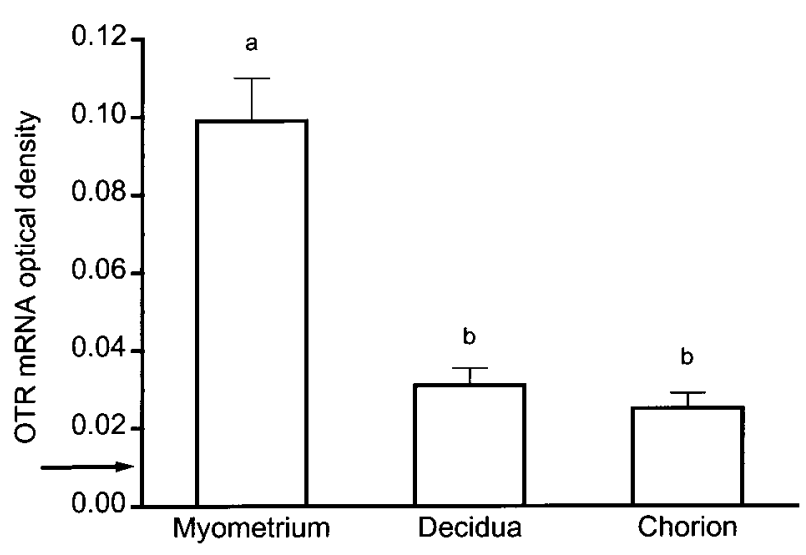

Figure 1 Effect of tissue type on OTR mRNA expression in tissue collected from pregnant women during the second half of gestation. Values from all samples analysed have been pooled for this analysis. The mean \pm S.E.M. OD was measured from autoradiographs for myometrium $(n=35)$, decidua $(n=27)$ and chorion $(n=22)$. ANOVA showed a highly significant effect of tissue type on OTR mRNA expression, $a>b \quad P<0 \cdot 001$. The arrow on the vertical axis denotes the detection limit.

\section{Data analysis}

Data were $\log$ transformed where necessary to achieve homogeneity of variance. Expression of OTR mRNA values between different tissue types (myometrium, decidua and chorion) was compared by one-way ANOVA. OTR mRNA expression in non-labour tissue from both myometrium and decidua was analysed by one-way ANOVA according to gestational age (24-28 weeks, 29-32 weeks, 33-36 weeks and 37 weeks onwards). The effect of labour on both OTR mRNA expression and ${ }^{125}$ I-OTA binding in myometrium and decidua was analysed by two-way ANOVA with gestation age (33-36 weeks and 37 weeks onwards) and labour status (labour or non-labour) as factors. Where ANOVA revealed significant effects, subsequent comparisons between sub-groups were made using Newman-Keuls tests. OD readings measured for both OTR mRNA expression and ${ }^{125}$ I-OTA binding in the same tissue samples were compared using Pearson's correlation analysis. A $P$ value of $<0.05$ was taken as indicative of significance.

\section{Results}

\section{Tissue type}

OTR mRNA was detected in myometrium, decidua and chorion (Fig. 1). Overall, there was a highly significant $(P<0 \cdot 001)$ effect of tissue type, with expression highest in myometrium and low levels in decidua and chorion. There was no detected expression in placental tissue (OD consistently $<0 \cdot 01)$. A similar pattern was observed with
${ }^{125}$ I-OTA binding (Fig. 2) and OD readings from the same samples measured using the two different techniques were highly correlated (correlation coefficient 0.642, 20 degrees of freedom, $P<0 \cdot 01)$. Although there was apparently high OTR mRNA expression in amnion collected from some patients, this was also often present in the sense controls. A similar problem occurred for the ${ }^{125} \mathrm{I}-\mathrm{OTA}$ binding which could not consistently be displaced by cold OT (Fig. 2). In both cases the signal was therefore regarded as non-specific and was not quantified.

\section{Gestational age}

OTR mRNA expression in myometrium from nonlabour patients collected at term was significantly higher than that measured in the preterm samples (Figs 3 and 4a). On the emulsions in term samples of myometrium the grains were seen in clusters rather than as individual grains (Fig. 5). When samples from decidua collected at all time points from 24 weeks to term were analysed together, there was no overall effect of gestation stage (Fig. 4b). In the samples collected at $<33$ weeks of gestation there was no significant difference in the OTR mRNA concentration in myometrium and decidua. There was a slight difference at 33-36 weeks (OD in myometrium $0 \cdot 041 \pm 0 \cdot 003, n=11$, decidua $0 \cdot 017 \pm 0 \cdot 003, n=7$, labour and non-labour samples combined, $P<0 \cdot 05)$ and a marked difference at term following the increase in OTR mRNA in the myometrium at this time (Fig. 4).

${ }^{125}$ I-OTA binding was only measured in samples collected after 33 weeks of gestation. Binding was already high in myometrium at 33-36 weeks and did not increase further at term (Fig. 6a). There was also no change in decidual binding during this period (Fig. 6b).

\section{Onset of labour}

The onset of labour was not accompanied by a significant change in expression of OTR mRNA or ${ }^{125}$ I-OTA binding in either myometrium or decidua in either term or preterm samples (Figs 2-6).

\section{Discussion}

These results have confirmed previous studies where OTR mRNA or OT binding sites were identified in pregnant human myometrium (Fuchs et al. 1984, Kimura et al. 1996), decidua (Fuchs et al. 1984, Takemura et al. 1994) and chorion, but were not present in placental tissue (Takemura et al. 1994). Our data have extended these findings by systematic determination of gestation- and labour-associated effects on both OTR mRNA and OT binding sites.

In myometrium there was a significant effect of gestational age, with myometrial OTR mRNA concentrations 

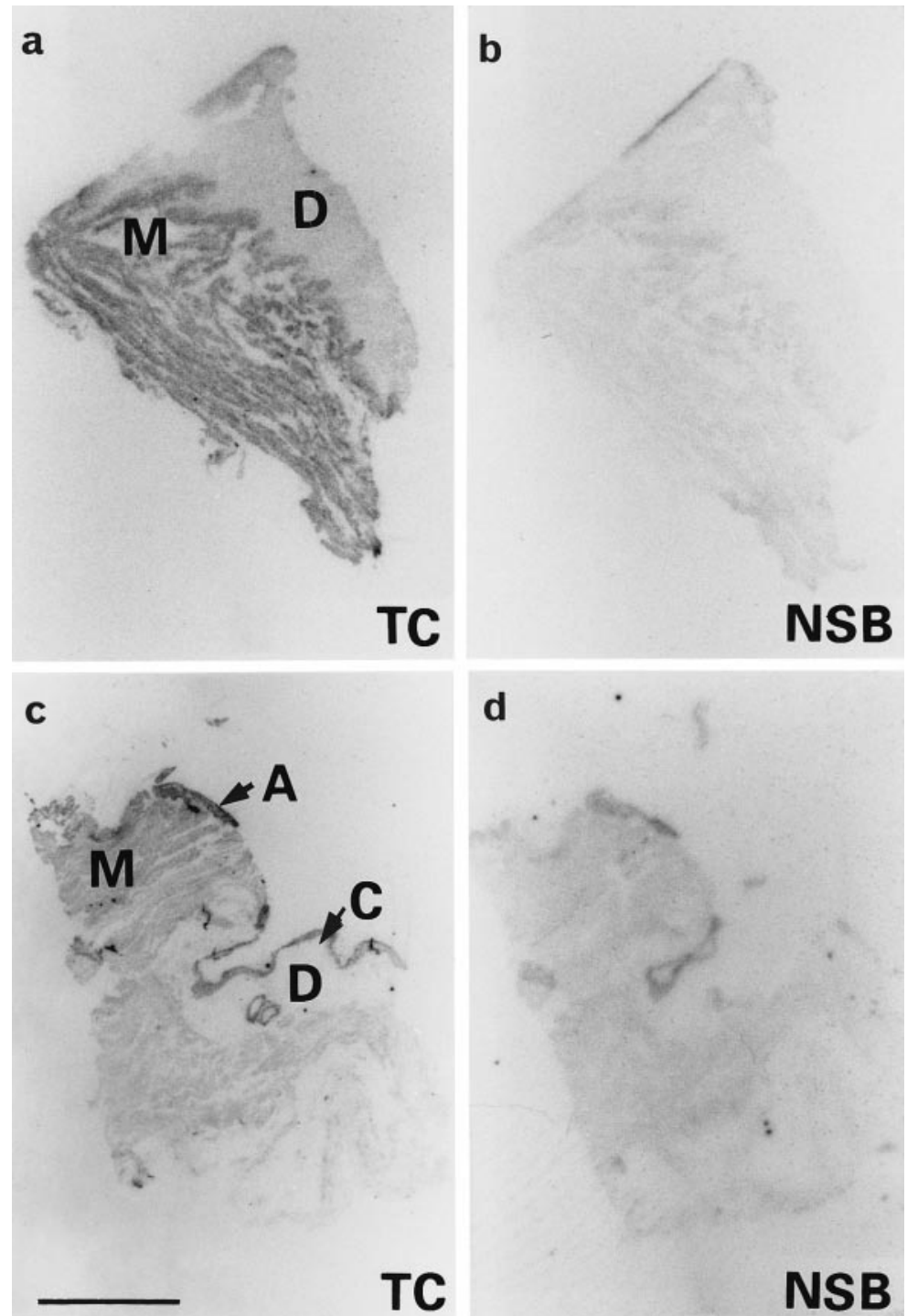

Figure $2{ }^{125}$ I-OTA binding in human uterine tissues treated with OT antagonist either alone (total counts, TC) or in the presence of excess unlabelled OT (NSB). ( $\mathrm{a}$ and b) Myometrium (M) and decidua (D) from a term labour sample. (c and d) Myometrium, decidua, amnion (A) and chorion (C) from a preterm (33-36 weeks) non-labour sample. The scale bar represents $5 \mathrm{~mm}$.

increasing after 37 weeks. This supports previous data from binding studies (Fuchs et al. 1984) and Northern blot analyses (Kimura et al. 1996). Fuchs et al. (1984) reported a further increase in OTR number after the onset of labour, whereas there was an apparent fall in concentration in advanced labour (Fuchs et al. 1984, Rivera et al. 1990, Bossmar et al. 1994). We found no change in mRNA concentrations associated with either term or preterm labour. The reasons for these differences are uncertain but could reflect variations in the exact timing or site of tissue collection. Although there are differences between studies, it appears unlikely from the work reported that a late increase in myometrial OTRs is one of the factors which acutely regulates the timing of labour onset in the human. This view is supported by the study of Takahashi et al. (1980), which showed a gradual increase in the myometrial sensitivity to OT between 32 weeks of gestation and full term.

In general there was a high degree of similarity between the results produced by in situ hybridization and autoradiography with ${ }^{125}$ I-OTA in terms of both localization and quantification of OTRs. The exception to this was the 

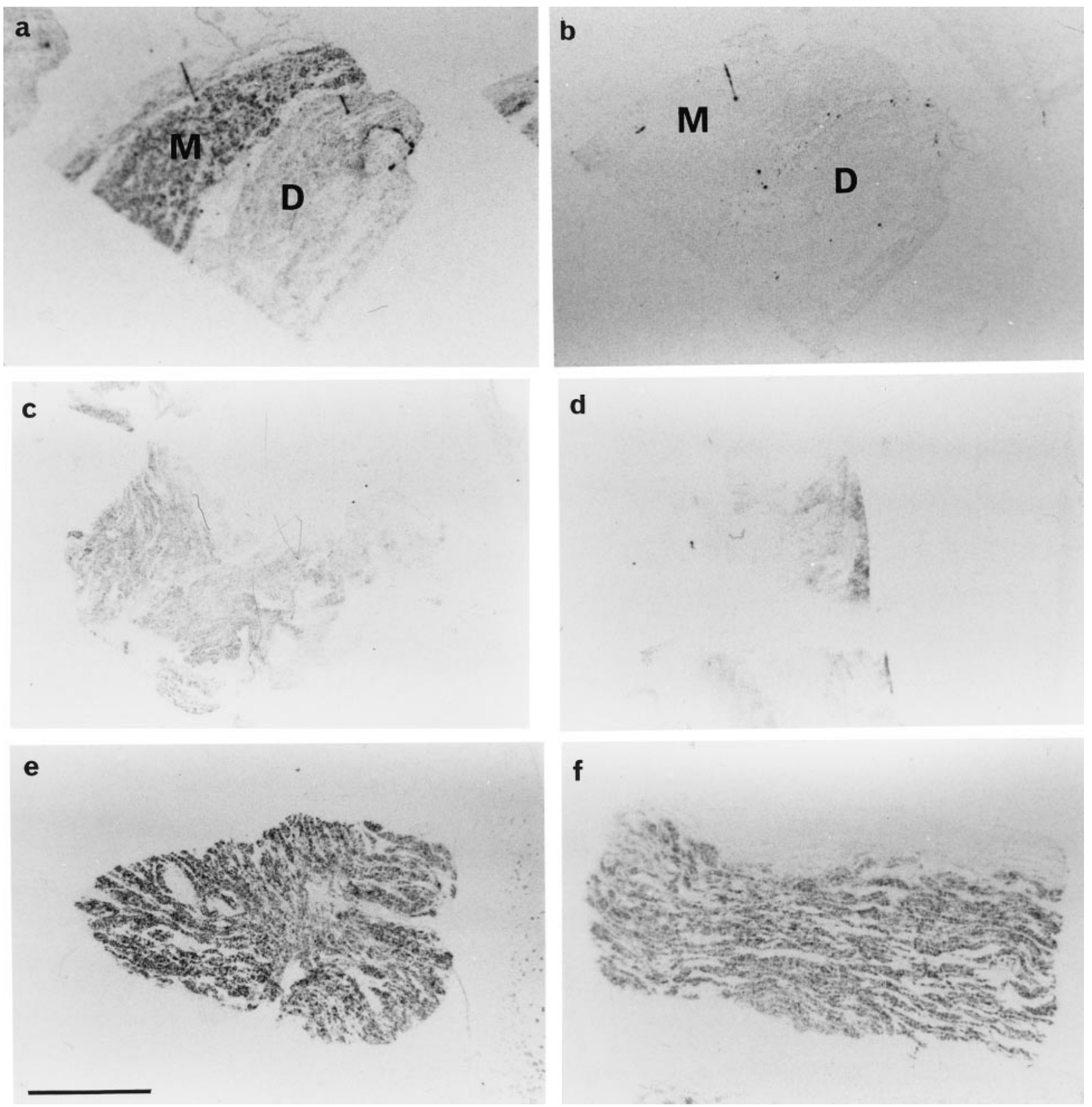

Figure 3 In situ hybridization showing autoradiographs of OTR mRNA expression in human uterine tissues. (a and b) Uterus collected from term non-labour treated with a ${ }^{35}$ S-labelled antisense (a) or sense control (b) probe, showing the myometrium (M) and decidua (D). The remaining sections were all treated with the antisense probe and show myometrium obtained from (c) preterm (24-28 weeks) non-labour, (d) preterm (28-36 weeks) labour, (e) term non-labour, and (f) term labour. The scale bar represents $5 \mathrm{~mm}$.

results relating to ${ }^{125}$ I-OTA binding in the myometrium, which did not increase at term. This may imply that translation of message into protein within the myometrium is proceeding more efficiently earlier in gestation. Alternatively, it may represent a methodological problem as it is difficult to obtain complete displacement of
${ }^{125}$ I-OTA with cold OT, so this method may be less quantitative than that used to measure the mRNA.

Fuchs et al. (1984) suggested that the number of decidual OT binding sites increased slightly at the end of pregnancy. Using Northern blot analysis (Takemura et al. 1994), this possible rise was attributed to an increase in 

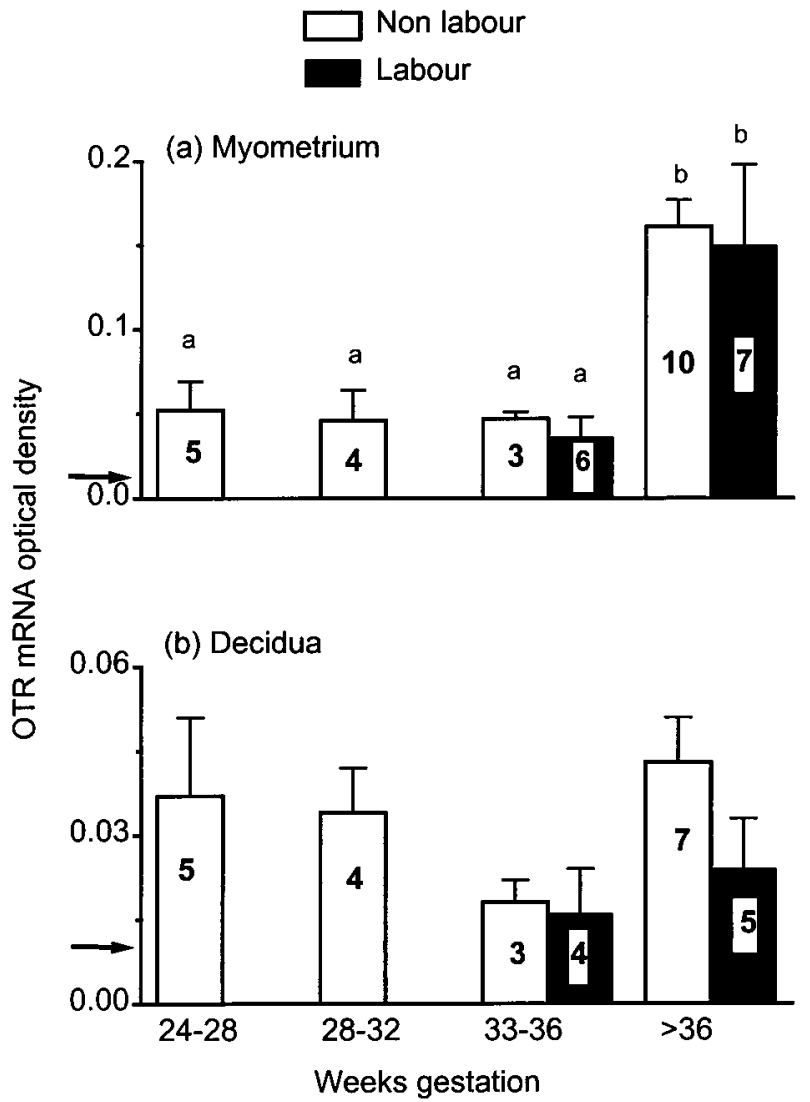

Figure 4 OD measurements of OTR mRNA expression in (a) myometrium and (b) decidua from samples collected at different stages of gestation from women not in labour or in labour. Note the difference in scale between the two graphs. The arrows on the vertical axes denote the detection limit. Values are the mean \pm S.E.M. The number of samples analysed at each time point is indicated on the figure. For myometrium there was a highly significant effect of gestation stage on OTR mRNA expression $(b>a, P<0.001)$ but no effect of labour. For decidua there was no effect of gestation or labour.

OTR mRNA transcription in decidual tissue from women in labour, although only three samples were obtained prior to labour onset. Our study included a greater number of preterm and non-labour samples. There was a slight tendency for OTR mRNA concentrations to increase between 33 and 36 weeks and term, but overall there was no significant change in the last trimester of pregnancy. Our work agrees with that of Fuchs et al. (1984) in that there was also no significant change in decidual OTRs associated with labour onset. It has been suggested that decidual cells lying proximal to the myometrium have higher expression than those closer to the chorion (Takemura et al. 1994). However, this was not observed in the present study, where OTR mRNA was uniform across sections of the decidua.

Overall these data suggest that OTRs are present in decidua but do not show major regulatory changes during the second half of pregnancy. OT does, however, have a clear stimulatory effect on decidual production of both prostaglandin $(\mathrm{PG}) \mathrm{F}_{2 \alpha}$ and $\mathrm{PGE}$ in vitro (Fuchs et al. 1981). It was proposed that the increase in plasma 13,14-dihydro15-keto-PGF ${ }_{2 \alpha}$ following OT induction of labour was attributable to decidual PG synthesis (Husslein et al. 1981). Furthermore, the ability of OT to release $\left[{ }^{3} \mathrm{H}\right]$ arachidonic acid from decidual cells is significantly greater in tissue collected from women in labour compared with those not in labour (Wilson et al. 1988). This may reflect an increased capacity for PG synthesis by the decidua at this time rather than an increase in OTRs.

OT binding sites have also been reported in amnion (Fukai et al. 1984) and in vitro studies have shown that OT can activate the inositol phospholipid signalling system and stimulate $\mathrm{PGE}_{2}$ production in cultured amnion (Moore et al. 1988, 1991). We were unable to confirm the presence of OTRs in amnion from our data because of NSB and non-specific hybridization to this tissue type, but this remains another potential target tissue for OT.

It is not currently known how the increase in OTR mRNA concentrations in the myometrium is regulated. Oestrogen has generally been shown to be stimulatory and progesterone inhibitory (Mitchell \& Challis 1988, Vallet et al. 1990, Zingg et al. 1995). Analysis of the human OTR promoter did not, however, reveal any classical palindromic oestrogen response elements although several half palindromic motifs are present (Kimura 1995, Zingg et al. 1995). It is possible that these might act synergistically to enable oestradiol to stimulate OTR gene transcription directly, although the antagonistic effect of progesterone is probably not mediated at the genomic level. A recent study has suggested that the progesterone metabolite $5 \beta$-dihydroprogesterone may prevent OT binding to the human receptor by a direct, non-genomic interaction with the OTR (Grazzini et al. 1998). In other species (e.g. sheep and rat) parturition is preceded by a decrease in progesterone and an increase in circulating oestradiol leading to a significant shift in the oestrogen:progesterone ratio (Mitchell \& Challis 1988). In contrast, there is no obvious trend in circulating steroid concentrations linked to OTR expression in human labour (Casey \& MacDonald 1988). In addition, the OTR promoter contains acute phase response elements which are normally activated by stress and inflammation (Kimura 1995, Rozen et al. 1995, Zingg et al. 1995). These could potentially be involved in the premature induction of labour associated with uterine infection (Romero et al. 1994, Kelly 1996) but it is not yet known whether they play a part in the regulation of OTR gene expression in normal human labour.

In conclusion, OTRs are present in the decidua, chorion and myometrium throughout the second half of human pregnancy with the highest expression in the myometrium. Myometrial OTR mRNA concentrations 

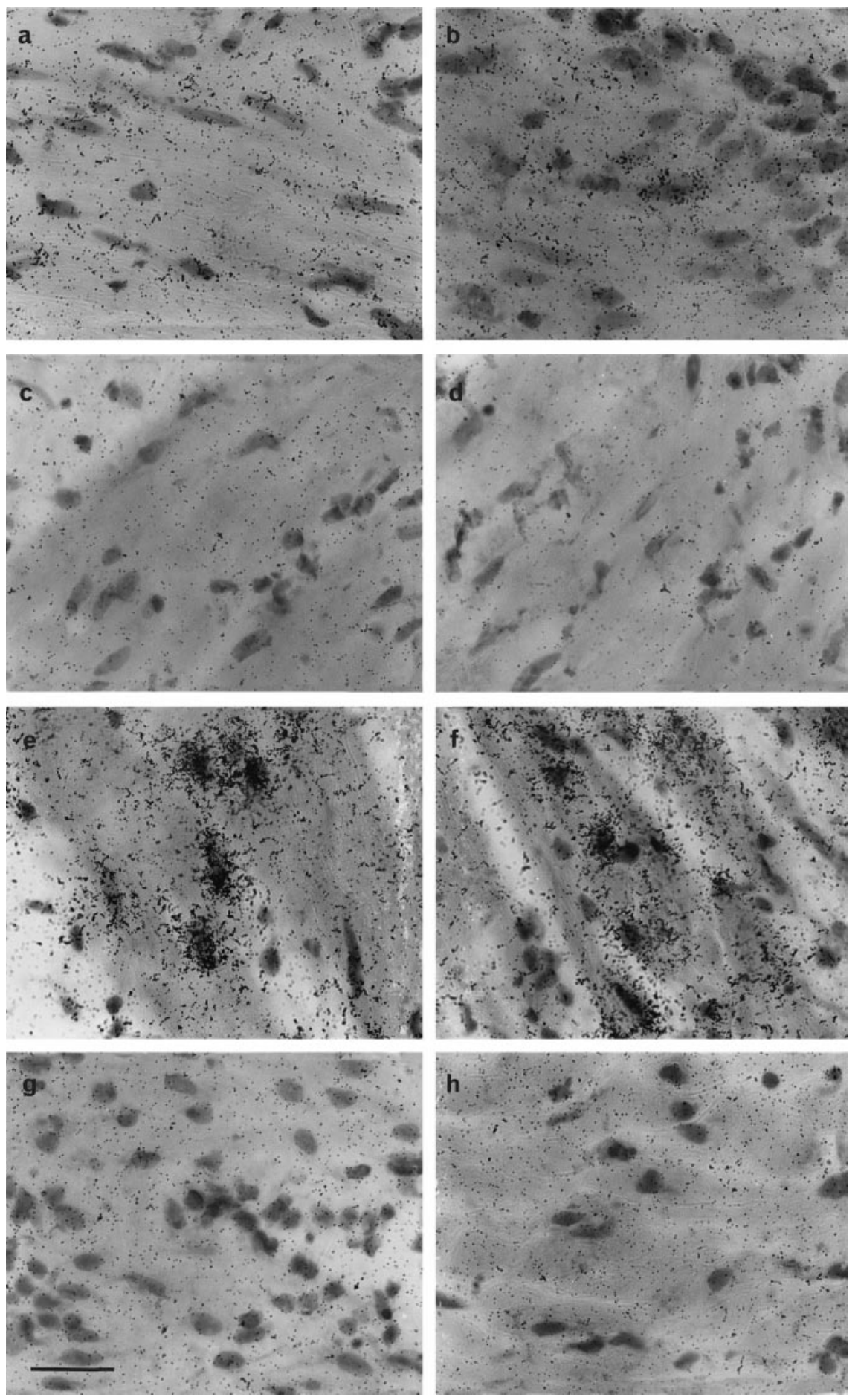

Figure 5 In situ hybridization of emulsion-coated slides of OTR mRNA expression in human myometrium treated with antisense ( $a, b$, e and f) or sense (c, d, g and h) probes. The sections were taken from the same specimens as those illustrated in Fig. $3 \mathrm{c}-\mathrm{f}$. (a and c) Preterm (24-28 weeks) non-labour, (b and d) preterm (28-36 weeks) labour, (e and g) term non-labour, and ( $f$ and $h$ ) term labour. The photographs show the increase in expression at term but not with labour. The scale bar represents $200 \mu \mathrm{m}$. 
Non labour

Labour

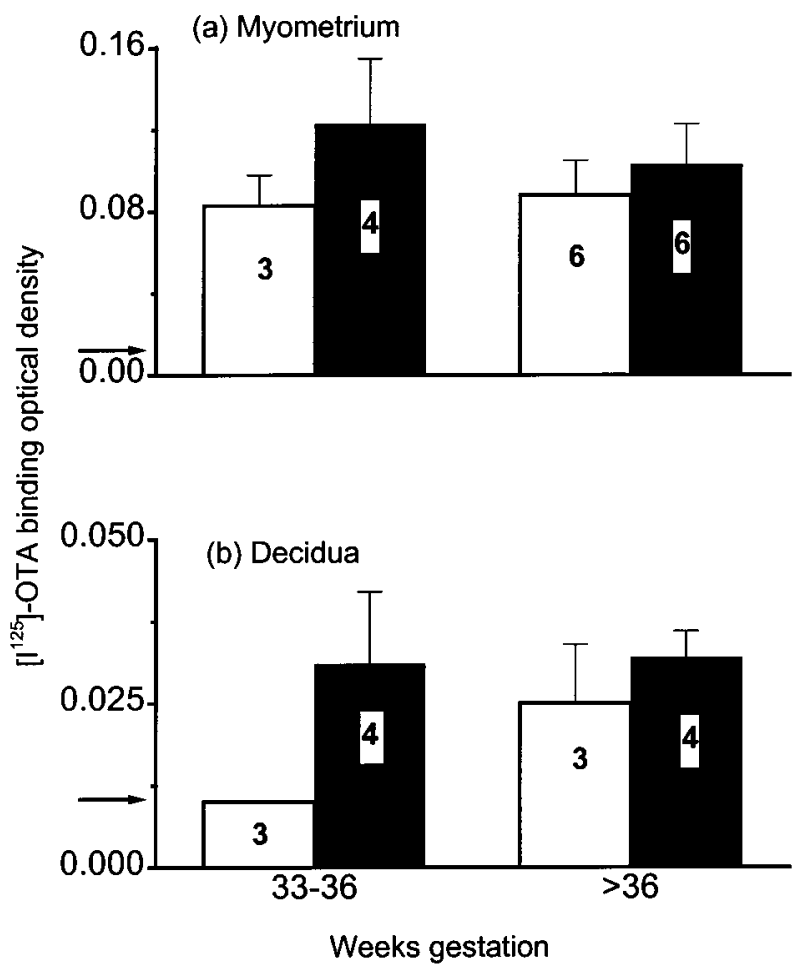

Figure 6 OD measurements of ${ }^{125}$ I-OTA binding in myometrium and decidua from samples collected at different stages of gestation from women not in labour or in labour. Note the difference in scale between the two graphs. The arrows on the vertical axes denote the detection limit. Values are the mean \pm S.E.M. The number of samples analysed at each time point is indicated on the figure. There was no significant effect of gestation stage or labour on ${ }^{125}$ I-OTA binding.

increase in late gestation ( $>36$ weeks) but there is no further rise associated with the onset of labour.

\section{Acknowledgements}

This work was supported by Wellbeing. We thank midwifery, theatre and medical staff at the Rosie Maternity Hospital, Cambridge, for assistance with the collection of tissue and Mrs B Wilsmore for photography. S T gratefully acknowledges the Medical Research Council for the provision of an MRC Clinical Scientist fellowship.

\section{References}

Ayad VJ, Guldenaar SEF \& Wathes DC 1991 Characterization and localization of oxytocin receptors in the uterus and oviduct of the non-pregnant ewe using an iodinated receptor antagonist. Journal of Endocrinology 128 187-195.
Bossmar T, Akerlund M, Fantoni G, Szamatowicz J, Melin P \& Maggi M 1994 Receptors for and myometrial responses to oxytocin and vasopressin in preterm and term human pregnancy: effects of the oxytocin antagonist atosiban. American Journal of Obstetrics and Gynecology 171 1634-1642.

Casey LM \& MacDonald PC 1988 Biomolecular processes in the initiation of parturition: decidual activation. Clinical Obstetrics and Gynecology 31 533-552.

Chibbar R, Miller FD \& Mitchell BF 1993 Synthesis of oxytocin in amnion, chorion, and decidua may influence the timing of human parturition. Journal of Clinical Investigation 91 185-192.

Fuchs AR, Husslein P \& Fuchs F 1981 Oxytocin and the initiation of human parturition. II. Stimulation of prostaglandin production in human decidua by oxytocin. American Journal of Obstetrics and Gynecology 141 694-697.

Fuchs AR, Fuchs F, Husslein P, Soloff MS \& Fernstrom MJ 1982 Oxytocin receptors and human parturition: a dual role for oxytocin in the initiation of labor. Science 215 1396-1398.

Fuchs AR, Fuchs F, Husslein P \& Soloff MS 1984 Oxytocin receptors in the human uterus during pregnancy and parturition. American Journal of Obstetrics and Gynecology 150 734-741.

Fukai H, Den K, Sakamoto H, Kodaira H, Uchida F \& Takagi S 1984 Study of oxytocin receptor: oxytocin and $\mathrm{PGF}_{2 \alpha}$ receptors in human myometria and amnion-decidua complex during pregnancy and labor. Endocrinologica Japonica 31 565-570.

Grazzini E, Guillon G, Mouillac B \& Zingg HH 1998 Inhibition of oxytocin receptor function by direct binding of progesterone. Nature 392 509-512.

Husslein P, Fuchs AR \& Fuchs F 1981 Oxytocin and the initiation of human parturition. I. Prostaglandin release during induction of labor by oxytocin. American Journal of Obstetrics and Gynecology 141 688-693.

Inoue $\mathrm{T}$, Kimura $\mathrm{T}$, Azuma $\mathrm{C}$, Inazawa J, Takemura $\mathrm{M}$, Kikuchi $\mathrm{T}$, Kubota Y, Ogita K \& Saji F 1994 Structural organization of the human oxytocin receptor gene. Journal of Biological Chemistry 269 32451-32456.

Kelly RW 1996 Inflammatory mediators and parturition. Reviews of Reproduction 1 89-96.

Kimura T 1995 Investigation of the oxytocin receptor at the molecular level. Advances in Experimental Medicine and Biology 395 259-268.

Kimura T, Takemura M, Nomura S, Nobunaga T, Kubota Y, Inoue T, Hashimoto K, Kumazawa I, Ito Y, Ohashi K, Koyama M, Azuma C, Kitamura Y \& Saji F 1996 Expression of oxytocin receptor in human pregnant myometrium. Endocrinology 137 780-785.

Leake RD, Weitzzman RE, Glatz TH \& Fisher DA 1981 Plasma oxytocin concentrations in men, nonpregnant women, and pregnant women before and during spontaneous labor. Journal of Clinical Endocrinology and Metabolism 53 730-733.

Mitchell BF \& Challis JRG 1988 Estrogen and progesterone metabolism in human fetal membranes. In Physiology and Biochemistry of Human Fetal Membranes, pp 5-28. Ed. BF Mitchell. Ithaca, NY: Perinatology Press.

Moore JJ, Dubyak GR, Moore RM \& Kooy DV 1988 Oxytocin activates the inositol-phospholipid protein kinase-C system and stimulates prostaglandin production in human amnion cells. Endocrinology 123 1771-1777.

Moore JJ, Moore RM \& Vanderkooy D 1991 Protein kinase-C activation is required for oxytocin induced prostaglandin production in human amnion cells. Journal of Endocrinology and Metabolism $\mathbf{7 2}$ 1073-1080.

Rivera A, Lopez Bernal A, Varney M \& Watson SP 1990 Inositol 1,4,5-trisphosphate and oxytocin binding in human myometrium. Endocrinology 127 155-162.

Romero R, Monoz H, Gomez R, Galasso M, Sherer DM, Cotton D \& Mitchell M 1994 Does infection cause premature labor and delivery? Seminars in Reproductive Endocrinology 12 227-239. 
Rozen F, Russo C, Banville D \& Zingg HH 1995 Structure, characterization and expression of the rat oxytocin receptor gene. Proceedings of the National Academy of Sciences of the USA 92 200-204.

Soloff MS, Alexandrova M \& Fernstrom MJ 1979 Oxytocin receptors: triggers for parturition and lactation? Science 204 1313-1314.

Stevenson KR, Riley PR, Stewart HJ, Flint APF \& Wathes DC 1994 Localization of oxytocin receptor mRNA in the ovine uterus during the oestrous cycle and early pregnancy. Journal of Molecular Endocrinology 12 93-105.

Takahashi K, Diamond F, Bieniarz J, Yen H \& Burd L 1980 Uterine contractility and oxytocin sensitivity in preterm, term and posterm pregnancy. American Journal of Obstetrics and Gynecology 136 774-779.

Takemura M, Kimura T, Nomura S, Makino Y, Inoue T, Kikuchi T, Kubota Y, Tokugawa Y, Nobunaga T, Kamiura S, Onoue H, Azuma C, Saji F, Kitamura Y \& Tanizawa O 1994 Expression and localization of human oxytocin receptor mRNA and its protein in chorion and decidua during parturition. Journal of Clinical Investigation 93 2319-2323.
Thorburn GD \& Challis JRG 1979 Endocrine control of parturition. Physiological Reviews 59 863-917.

Thornton S, Davison JM \& Baylis PH 1992 Plasma oxytocin during the first and second stages of spontaneous human labour. Acta Endocrinologica 126 425-429.

Vallet JL, Lamming GE \& Batten M 1990 Control of endometrial oxytocin receptor and uterine response to oxytocin by progesterone and oestradiol in the ewe. Journal of Reproduction and Fertility 90 625-634.

Wilson T, Liggins GC \& Whittaker DJ 1988 Oxytocin stimulates the release of arachidonic acid and prostaglandin $\mathrm{F}_{2 \alpha}$ from human decidual cells. Prostaglandins 35 771-780.

Zingg HH, Rozen F, Breton C, Larcher A, Neculcea J, Chu K, Russo C \& Arslan A 1995 Gonadal steroid regulation of oxytocin and oxytocin receptor gene expression. Advances in Experimental Medicine and Biology 395 395-404.

Received 29 July 1998

Accepted 18 November 1998 